\title{
Assessment of total phenolic and flavonoid contents and potential biological efficacy of few Pinus species growing in Northern Himalayas
}

\author{
Lav SINGH ${ }^{1,2}$ \\ Pooja DIXIT ${ }^{1}$ \\ Atul Kumar UPADHYAY ${ }^{3}$ \\ Ravi Prakash SRIVASTAVA ${ }^{1}$ \\ Shivaraman PANDEY ${ }^{4}$ \\ Praveen Chandra VERMA ${ }^{5}$ \\ Gauri SAXENA $^{1}(\square)$
}

\section{Summary}

Environmental interventions and ecological adaptations harbor millions of valued substances and metabolites in plants which can be employed and commercialized for human benefits. Present study encompasses the untapped potential of pine needles of Indo-Himalayan region for the production of different metabolites and their pharmacological significance in terms of antioxidant and antimicrobial activity. Total phenolic and flavonoid content from the needles of ten pine species was quantified using three different solvent systems. Results revealed that out of 10 different selected Pinus species, Pinus taeda L. showed the highest concentration of total phenolics, Soluble-F phenolics and flavonoids content (approx. 147.02 $\mathrm{mg} / \mathrm{g}, 141.08 \mathrm{mg} / \mathrm{g}$ and $21.91 \mathrm{mg} / \mathrm{g}$, respectively) as compared to other species. On the other hand, Pinus greggii Engelm. ex Parl. showed the highest Bound-W phenolic content (approx. $3.62 \mathrm{mg} / \mathrm{g}$ ). Among all the selected plant species, the needles of Pinus echinata Mill. exhibited the highest and Pinus thunbergii Parl. had the lowest ratio of total flavonoids to total phenolics. Most of these compounds were found to have effective antioxidant activities as well as antimicrobial activity, as estimated by oxygen radical absorbance capacity (ORAC) and disk diffusion test, respectively.

\section{Key words}

Pinus, needle, Himalayas, phenolics, flavonoids, antimicrobial, antioxidant

${ }^{1}$ Department of Botany, University of Lucknow, Lucknow, India

${ }^{2}$ PG Department of Botany, RD \& DJ College, Munger University, Munger, India

${ }^{3}$ Department of Environmental Science, Babasaheb Bhimrao Ambedkar University, Lucknow 226025, India

${ }^{4}$ Plant Diversity, Systematics and Herbarium Division, CSIR-National Botanical Research Institute, Lucknow, India

${ }^{5}$ Plant Molecular Biology and Genetic Engineering Division, CSIR-National Botanical Research Institute, Lucknow, India

Corresponding author: gaurigupta72@yahoo.com

Received: April 12, 2020 | Accepted: May 21, 2020

ACS

Agric. conspec. sci. Vol. 85 (2020) No. 4 (335-344) 


\section{Introduction}

In order to protect themselves against an array of pathogenic attacks and oxidative stress, plants produce diverse phytochemicals called secondary metabolites. Such secondary metabolites possess several ecological and biological activities viz., anti-inflammatory, anti-oxidant and antimicrobial. In addition, they also exhibit a wide spectrum of actions such as anti-mutagenic, antitumor as well as protective against oxidative DNA damage, and apoptosis induced by hydroxyl radicals (Kwak et al., 2006; Jeong et al., 2009; Kim et al., 2010). These compounds also play an important role in imparting attractive colors to flowers that help in attracting pollinators. Besides their biological, nutraceutical and clinical significance, flavonoids are also involved in various plant defense mechanisms (Stafford, 1988). Such bioactive defense compounds are also important when it comes to plant responses against environmental hazards, such as pollution, temperature fluctuations and UV radiations (Tegelberg et al., 2004). Phenolic compounds show great variations after high temperature shocks to stems and crown, proving their importance as bioindicators of thermal stress (Alonso et al., 2002). These plant-based metabolites are of enormous scientific interest. Phenolics and flavonoids are the largest category of such phytoconstituents and are most common. The use of phenolic and flavonoid based plant metabolites requires large-scale sources of these plants to satisfy considerable industrial demands.

The Himalayas, one of the hotspots of biodiversity, are also one of the richest ecosystems on earth with a variety of species and forest types due to the varying altitudes, topography and climatic conditions and harbor nearly 8,000 species of higher plants, of which $25.3 \%$ are endemic (Singh and Hajra, 1996) and cover about $12.84 \%$ of the total geographical area of India (Negi, 2009). With over 105 species, Pinus is the most dominant genus of the family Pinaceae belonging to gymnosperms and has a wide range of distribution and adaptability to diverse climatic conditions in Northern as well as Southern Hemisphere on the globe (Mehra, 1988). The pine species growing in Himalayas are undoubtedly suiting industrial and pharmaceutical needs. From earliest times, this genus has been of great economic value due to its wood and the nutritional properties of its nuts. The value of this genus further increased with the development of industrial technologies as pines turned out to be an excellent source of oleoresin, which after processing yielded turpentine and colophony and pine needles and pine sprouts being raw materials for pine teas (Chung et al., 1996). However very little information is available about the phenolics and flavonoids of Indian species of Pinus. Most of the previous works done are either associated with chemistry and pharmacognotic aspects of bark or chemical composition and antimicrobial activity of essential oil distilled from needles of various pine species and their therapeutic value. Despite the increase in scientific data on the phenolic and flavonoid profile of pine species, a literature search revealed lack of information in Pinus species from the Indian Himalayan flora. Thus, the main objective of the current study was to quantify the total phenolics and flavonoids of ten selected species of Pinus. This study also examined the biological efficacy in different extracts of pine needles by assessing their antioxidant and antimicrobial capacity. The aim of study was to gather more information that may further clarify the role of secondary metabolites of Pinus in medicine and other commercial applications.

\section{Materials and methods}

\section{Chemicals}

Folin-Ciocaltau reagent, gallic acid, aluminum chloride and naringin were purchased from Sigma-Aldrich (United States) and ethyl alcohol, ethyl acetate, hydrochloric acid, sodium carbonate, sodium hydroxide, phosphate buffer $(\mathrm{pH} 7.0)$ and trolox reagent from Gyan Scientific (Lucknow, India).

\section{Collection and authentication of plant material}

The leaves (needles) of 10 pine species (out of these ten, five species Pinus merkusii Jungh. \& de Vriese, Pinus khasya Hook, Pinus thunbergii Parl., Pinus wallichiana A. B. Jacks. and Pinus roxburghii Sarg. are native to India and other five (Pinus taeda L., Pinus elliottii Engelm, Pinus echinate Mill., Pinus patula Schiede ex Schltdl. \& Cham. and Pinus greggii Engelm. ex Parl. are introduced or exotic and now growing luxuriantly) were collected in September, 2016, from a wild population in the region of Ranikhet (located at $357 \mathrm{~km}$ NSE of New Delhi: latitude 29³9'52.2" (N); longitude $79^{\circ} 28^{\prime} 40.9^{\prime \prime}$ (E); altitude $1570 \mathrm{~m}$ to $1986 \mathrm{~m}$ ). The site is characterized by an average temperature of $14.4^{\circ} \mathrm{C}$, median rainfall (approximately $1575 \mathrm{~mm}$ of precipitation annually) and low soil fertility. A voucher specimens of all the species selected for study were deposited in the herbarium of the National Botanical Research Institute, Lucknow and identified.

\section{Extract preparations}

Pine needle extracts and fractions were prepared by the method of Sun et al. (2002). For the preparation of Soluble-F (Soluble free), $1 \mathrm{~g}$ of dried pine needle powder was extracted with $150 \mathrm{ml}$ of chilled $80 \%$ acetone by blending with a UTL 25 digital Inline ULTRA-TURRAX four times, each time for $6 \mathrm{~min}$. Homogenates were filtered through filter paper (Whatman No. 42 ), and the filtrates were evaporated to dryness and reconstituted in $50 \mathrm{ml}$ of distilled water. For preparation of Bound-E (Ethyl acetate) fraction, the residues from Soluble $\mathrm{F}$ were collected and hydrolyzed with $20 \mathrm{ml}$ of $4 \mathrm{M} \mathrm{NaOH}$ at room temperature for 24 hr. After hydrolysis, the solutions were centrifuged for $8 \mathrm{~min}$ at $5000 \mathrm{rpm}$. The supernatant was neutralized with concentrated hydrochloric acid and extracted three times with ethyl acetate. Ethyl acetate extracts were then further evaporated to dryness and again suspended in $10 \mathrm{ml}$ of distilled water. To prepare Bound-W (Bound water), the remaining water-soluble portion was evaporated to dryness and then reconstituted in $10 \mathrm{ml}$ of water. All fractions were stored at $-80^{\circ} \mathrm{C}$ prior to total phenolic and total flavonoid content analysis. Extracts were prepared from needles of each species of Pinus, and each analysis was executed in triplicate.

\section{Estimation of total phenolic and flavonoid contents}

\section{Estimation of total phenolic}

Total phenolic content was estimated in a 96-well plate as per method of Zhang et al. (2006). An aliquot of $100 \mu$ l of the FolinCiocalteu reagent was added to $5 \mu$ of needle extract (concentration $1 \mu \mathrm{g} / \mu \mathrm{l})$, mixed thoroughly and kept for 10 minutes, followed by addition of $80 \mu \mathrm{l}$ of $7.5 \%$ sodium carbonate. The plate was then left at room temperature in the dark for 2 hours. 
Absorbance was measured at $750 \mathrm{~nm}$ on UV-vis spectrophotometer (Spectra scan UV 2700, Thermo Scientific). Gallic acid was used as standard in this estimation of phenolic content. Results were expressed as milligrams of gallic acid equivalent per gram of extract. Blanks were prepared for both the standard as well as extracts by replacing gallic acid and plant extract with Milli-Q water.

\section{Calculations}

A standard curve was constructed with gallic acid of concentration ranging from $0.5 \mu \mathrm{g} / \mathrm{ml}$ to $4 \mu \mathrm{g} / \mathrm{ml}$. The concentration of all the unknown samples were then calculated based on the equation of the standard curve which was

$$
\mathrm{y}=0.276 \mathrm{x}+0.104(\text { Figure } 1)
$$

\section{Estimation of total flavonoid}

Total flavonoid content in the needle of all the selected Pinus species were estimated as per the method of Chang et al. (1996.) An aliquot of $200 \mu \mathrm{l}$ of needle extract (concentration $1 \mu \mathrm{g} / \mu \mathrm{l}$ ) was added to $1.5 \mathrm{ml}$ of $95 \%$ ethyl alcohol. To this $0.1 \mathrm{ml}$ of $10 \%$ aluminium chloride was added followed by addition of $0.1 \mathrm{ml}$ of 1 $\mathrm{M}$ potassium acetate and $2.8 \mathrm{ml}$ of distilled water. The mixture was incubated at room temperature for 25 minutes and the absorbance was then recorded at $415 \mathrm{~nm} \mathrm{UV-vis} \mathrm{spectrophotometer} \mathrm{(Spectra}$ scan UV 2700, Thermo Scientific). The result was expressed as milligrams of Naringin equivalent per gram of needle extract.

\section{Calculation}

Naringin was used as a standard in this estimation. A standard curve was constructed with Naringin of concentration ranging from $5 \mu \mathrm{g}$ to $25 \mu \mathrm{g}$ in the reaction mixture. The concentration of all the unknown samples were then calculated based on the equation of the standard curve which was

$$
\mathrm{Y}=0.01 \mathrm{x}+0.013 \text { (Figure 1). }
$$

\section{Antioxidant activity}

The oxygen radical absorbance capacity (ORAC) of each fraction in selected pine needle extracts was measured using the method given by Yoon et al. (2010.). Soluble-F, Bound-E, and Bound-W pine needle extracts were diluted 50,000; 5000 and 5000 -fold, respectively, with $75 \mathrm{mM}$ phosphate buffer ( $\mathrm{pH} \mathrm{7.0)}$. A standard curve was obtained by plotting four concentrations of Trolox against the net area under the curve of each standard. Final ORAC values were calculated using the regression equation between Trolox concentration and AUC (area under curve) and are expressed as $\mu \mathrm{M}$ of Trolox equivalents per gram dry weight.

\section{Antimicrobial activity}

\section{Microbial strains}

Soluble free (Soluble-F), bound ethyl acetate (Bound-E) and bound water (Bound-W) fractions were individually tested against a panel of eight pathogenic microorganisms; six bacteria species, out of which two are gram positive: Staphylococcus aureus (MTCC 96), Streptococcus mutans (MTCC 890) and four are gram negative: Klebsiella pneumoniae (MTCC 109) Escherichia coli (MTCC 739), Salmonella typhimurium (MTCC 98), Pseudomonas aeruginosa (MTCC 741), and two fungal strains: Candida albicans (CA-3010) and SS=Sporothrix schenckii. All microorganisms were obtained from the Microbiological laboratory, Central Institute of Medicinal and Aromatic Plants (CSIR-CIMAP), Lucknow.

\section{Disc diffusion assay}

Antimicrobial activities of three extracts were first screened for their inhibitory zone by using agar disc diffusion assay. The microbial suspensions of selected bacterial and fungal species were prepared by diluting the cell mass in saline water $(0.9 \%$ $\mathrm{NaCl}$ ) and then it was adjusted to $0.5 \mathrm{McF}$ arland scale. $20 \mathrm{~mL}$ of sterile agar [Mueller Hinton for bacterial strains and Sabouraud dextrose agar for fungal strains] were poured in the petri plates

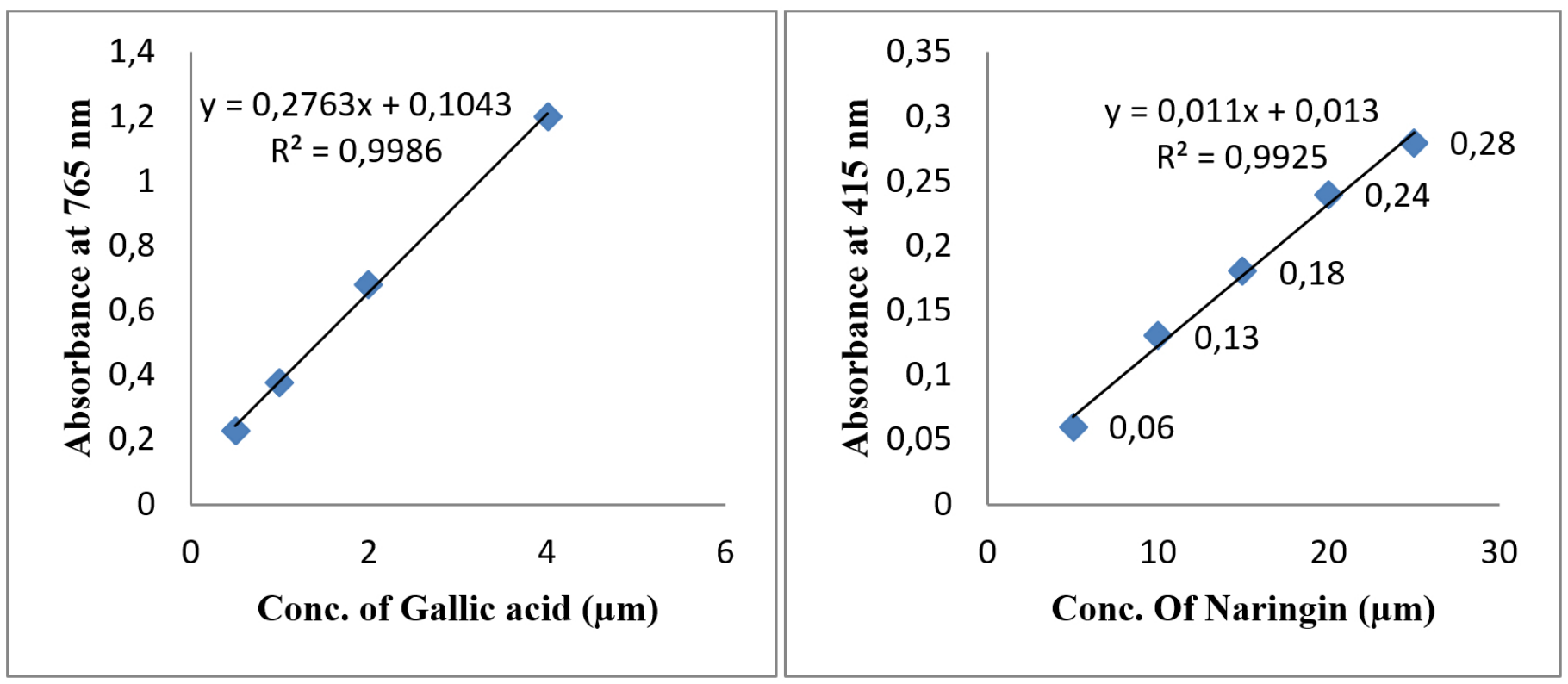

Figure 1. Standard curve with gallic acid of concentration ranging from $0.5 \mu \mathrm{g} / \mathrm{ml}$ to $4 \mu \mathrm{g} / \mathrm{ml}$ and with Naringin of concentration ranging from $5 \mu \mathrm{g}$ to $25 \mu \mathrm{g}$ in the reaction mixture 
and it was allowed to dry. The inoculums were scrubbed on the top of the media. Sterile paper discs (5.5 $\mathrm{mm}$ of paper) impregnated with $10 \mu \mathrm{l}$ of the plant extracts $(100 \mathrm{mg} / \mathrm{mL})$ were applied in the petri dish. Before incubation, all petri dishes were stored in the dark at $+4^{\circ} \mathrm{C}$ for two hours, so that diffusion of the extracts from disc to medium can take place without microbial growth. After incubation at $37^{\circ} \mathrm{C}$ for 24 hours and $30^{\circ} \mathrm{C}$ for 48 hours for bacteria and fungi, respectively, activity was determined by measuring the inhibitory zone diameter ID in $\mathrm{mm}$. The data used were the average of three replicates.

\section{Minimum inhibitory concentration (MIC)}

Minimum inhibitory concentration (MIC) is defined as the lowest concentration of the extract that prevents visible growth of microorganisms. It was determined by the agar dilution method as described by Ebrahimabadi et al. (2010). The appropriate quantity of the plant extract was added to the sterile medium to produce the concentration range of $25-0.097 \mathrm{mg}$ extract $/ \mathrm{mL}$ medium. The resulting agar solutions were immediately mixed and poured into the petri plates. The plates were spot inoculated with $1 \mu \mathrm{l}$ of microorganism.

\section{Results and Discussion}

Preliminary phytochemical analysis of various solvent extracts, such as extract soluble free (Soluble-F), bound ethyl acetate (Bound-E) and bound water (Bound-W), of needles of ten species of Pinus revealed the presence of several phenolics and flavonoids in varying quantities. These extracts show growth inhibitory activity against tested strains of bacteria and fungi.

\section{Total phenolics content}

The total phenolic content (Table 1 and Fig. 2) in needles of ten pine species was estimated using gallic acid as standard. Phenolic content was expressed as allic Acid Equivalent (GAE)/g of tissue. Among all pine species analyzed, $P$. taeda had the highest Soluble-F phenolic content $(141.08 \pm 2.34 \mathrm{mg} / \mathrm{g})$, followed by $P$. thunbergii $(139.67 \pm 0.89 \mathrm{mg} / \mathrm{g})$. Pinus khasya had the highest Bound-E phenolic content $(4.87 \pm 0.22 \mathrm{mg} / \mathrm{g})$, while the highest Bound-W phenolic content $(3.62 \pm 0.23 \mathrm{mg} / \mathrm{g})$ was found in $P$. greggii. Pinus taeda had the highest total phenolic (SolubleF+Bound-E+Bound-W) content $(147.02 \pm 3.28 \mathrm{mg} / \mathrm{g})$. Among three different extracts, soluble free (Soluble-F) extract showed maximum phenolic content ranging from $141.08 \pm 2.34 \mathrm{mg}$ of GAE/g in P. taeda to $38.08 \pm 2.96 \mathrm{mg}$ of GAE/g in P. roxburghii while water extract (Bound-W) showed minimum phenolic content. Results were expressed as mean \pm SD $(n=3)$. Phenolic compounds are often positively correlated with the antioxidant activity due to their capability to act as electron donors during free radical reactions (Velioglu et al., 1998). Variations in phenolic contents are often due to genetic differences. However, it has been observed that altitude and temperature are the major environmental factors that affect phytochemical profile of plants (Reiger et al., 2008). It was reported that the plant samples collected from lower temperature and higher altitude sites showed higher concentration of phenolic content (Wildi and Lutz, 1996). In the present work various species of Pinus were collected from

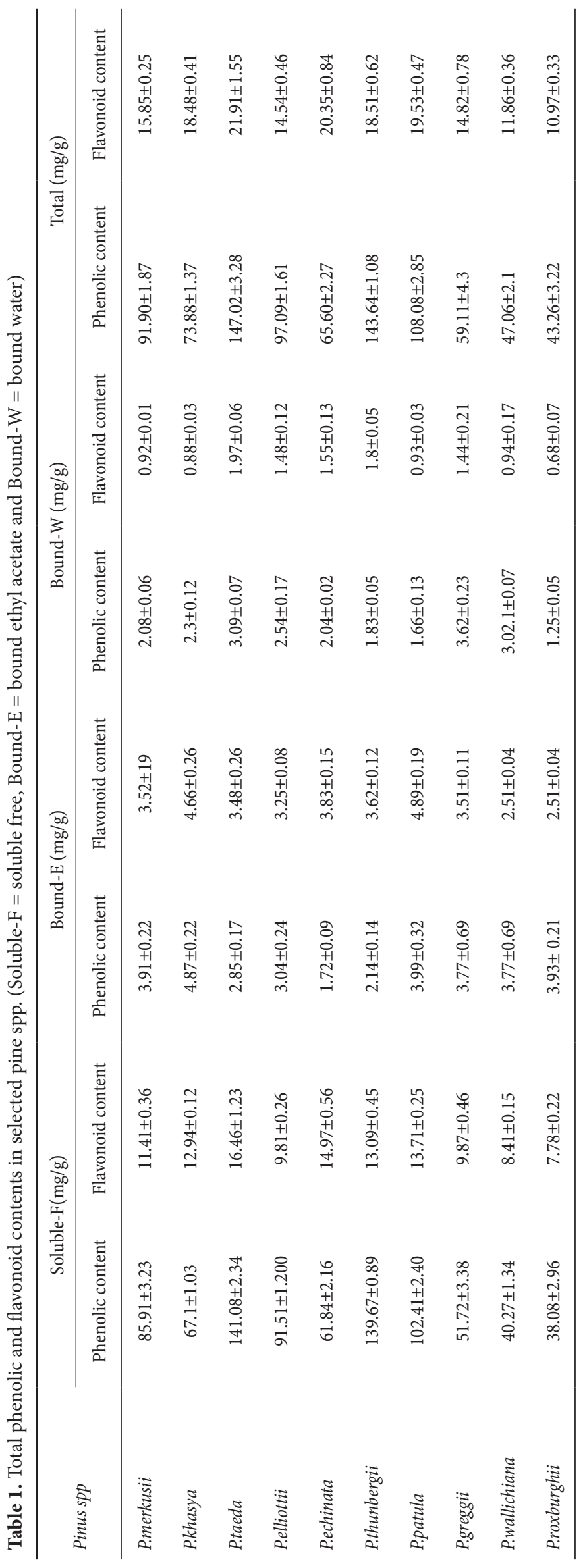




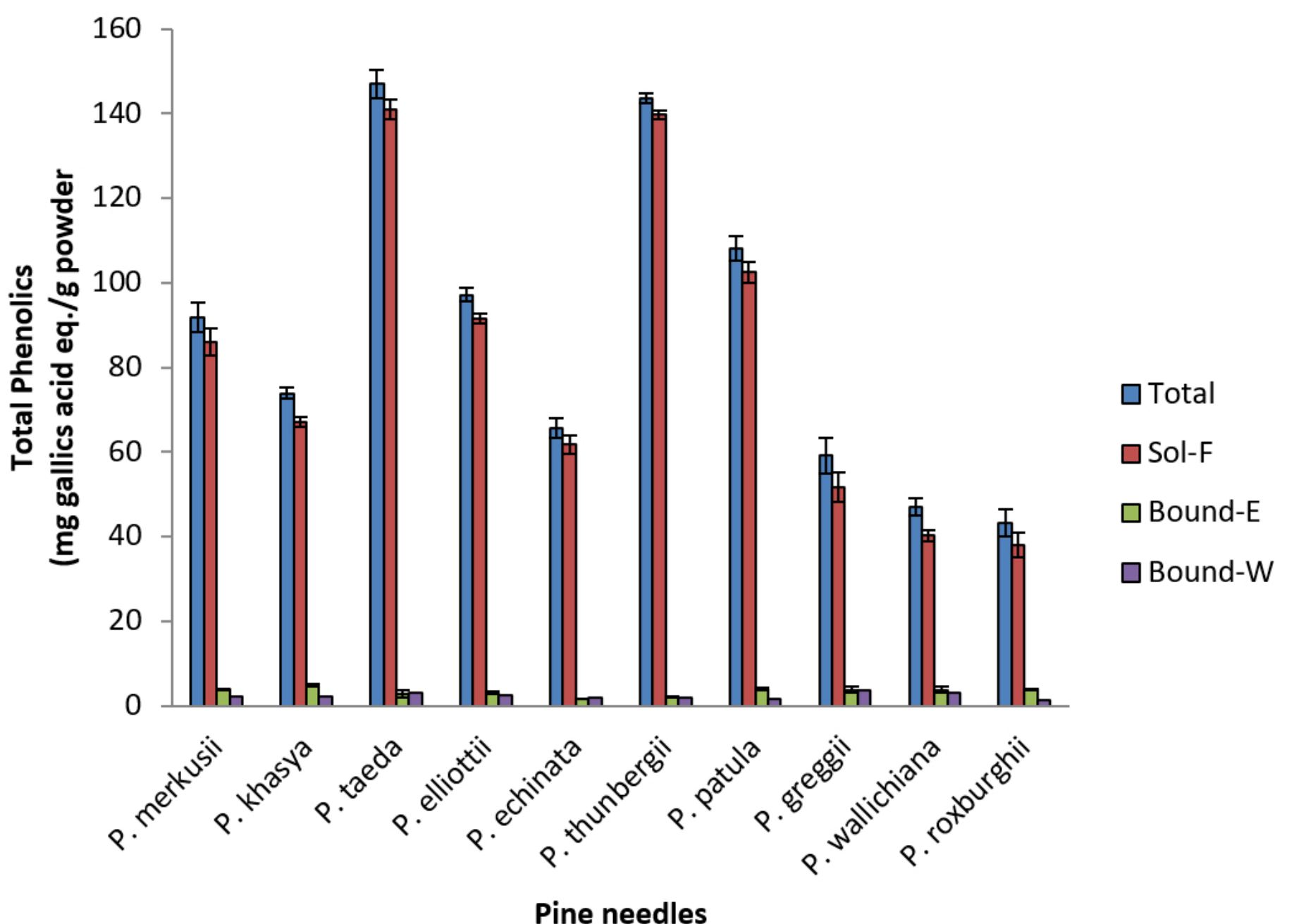

Figure 2. Total phenolics in soluble free (Soluble-F), bound ethyl acetate (Bound-E) and bound water (Bound-W) fractions from various pine needles. Values are mean \pm SD of triplicate measurements

same location thus the probability of variations that exist among them with respect to the contents of phenolics and flavonoids may be solely due to genetic differences within them.

\section{Total flavonoid content}

Among three different extracts, soluble free (Soluble-F) extract showed maximum flavonoids while water extract (Bound-W) showed minimum phenolic content (Table 1 and Fig. 3). Pinus taeda had the highest total flavonoid (Soluble-F+Bound-E+Bound-W) content $(21.91 \pm 1.55 \mathrm{mg} / \mathrm{g})$, followed by $P$. echinata $(20.35 \pm 0.84$ $\mathrm{mg} / \mathrm{g})$, and P. patula $(19.53 \pm 0.47 \mathrm{mg} / \mathrm{g})$. Among all the species, the pine needles of $P$. echinata had the highest and $P$. thunbergii had the lowest ratio of total flavonoids to total phenolics. Results are expressed as mean $\pm \operatorname{SD}(n=3)$. Flavonoids play very important role in providing bright colors to flowers, fruits and berries that facilitate pollination and make biosphere beautiful (Brouillard and Dangles, 1993). In addition to their biological, clinical and nutraceutical effects (Maimoona et al., 2011), flavonoids including proanthocyanidins are used in various plant defense mechanisms (Stafford, 1988).

\section{Antioxidant activity}

Antioxidant property in three extracts of pine needles belonging to ten species was estimated using oxygen radical absorbance capacity (ORAC) of extracts. Among three different extracts, soluble free (Soluble-F) extract showed maximum antioxidant activity, while water extract (Bound-W) exhibited minimum antioxidant activity (Fig. 4). Measurement of anti-oxidant activity in three extracts revealed that $P$. taeda had the highest Soluble-F antioxidant activity (1151.7 $\pm 13.7 \mu$ mole Trolox/g), followed by P. thunbergii (1036.6 $\pm 20.7 \mu$ mole Trolox/g), P. patula (913.4 \pm $21.4 \mu$ mole Trolox/g), P. merkusii (849.8 $\pm 30.1 \mu$ mole Trolox $/ g$ ), P. elliottii $(700.3 \pm 12.7 \mu$ mole Trolox/g), P. khasya $(659.3 \pm 34.9$ $\mu$ mole Trolox/g), P. echinata (629.9 $\pm 22.1 \mu$ mole Trolox/g), $P$. greggii (540.9 $\pm 17.1 \mu$ mole Trolox/g), P. roxburghii (419.2 \pm 17.3 $\mu$ mole Trolox/g) and P. wallichiana (406.6 $\pm 9.9 \mu$ mole Trolox/g ). Pinus khasya had the highest Bound-E antioxidant activity (144.4 $\pm 8.3 \mu$ mole Trolox/g), followed by $P$. patula $(128.6 \pm 6.4 \mu$ mole Trolox/g), P. merkusii $(120.1 \pm 3.7$ mole Trolox/g), P. roxburghii (117.6 $\pm 6.8 \mu$ mole Trolox/g), P. greggii (79.9 $\pm 8.2 \mu$ mole Trolox/g), P. wallichiana $(77.6 \pm 6.2 \mu \mathrm{mole}$ Trolox/g), P. taeda $(66.8 \pm 7.0 \mu \mathrm{mole}$ Trolox/g), P. elliottii $(66.3 \pm 5.7 \mu$ mole Trolox/g), P. echinata (54.4 \pm 


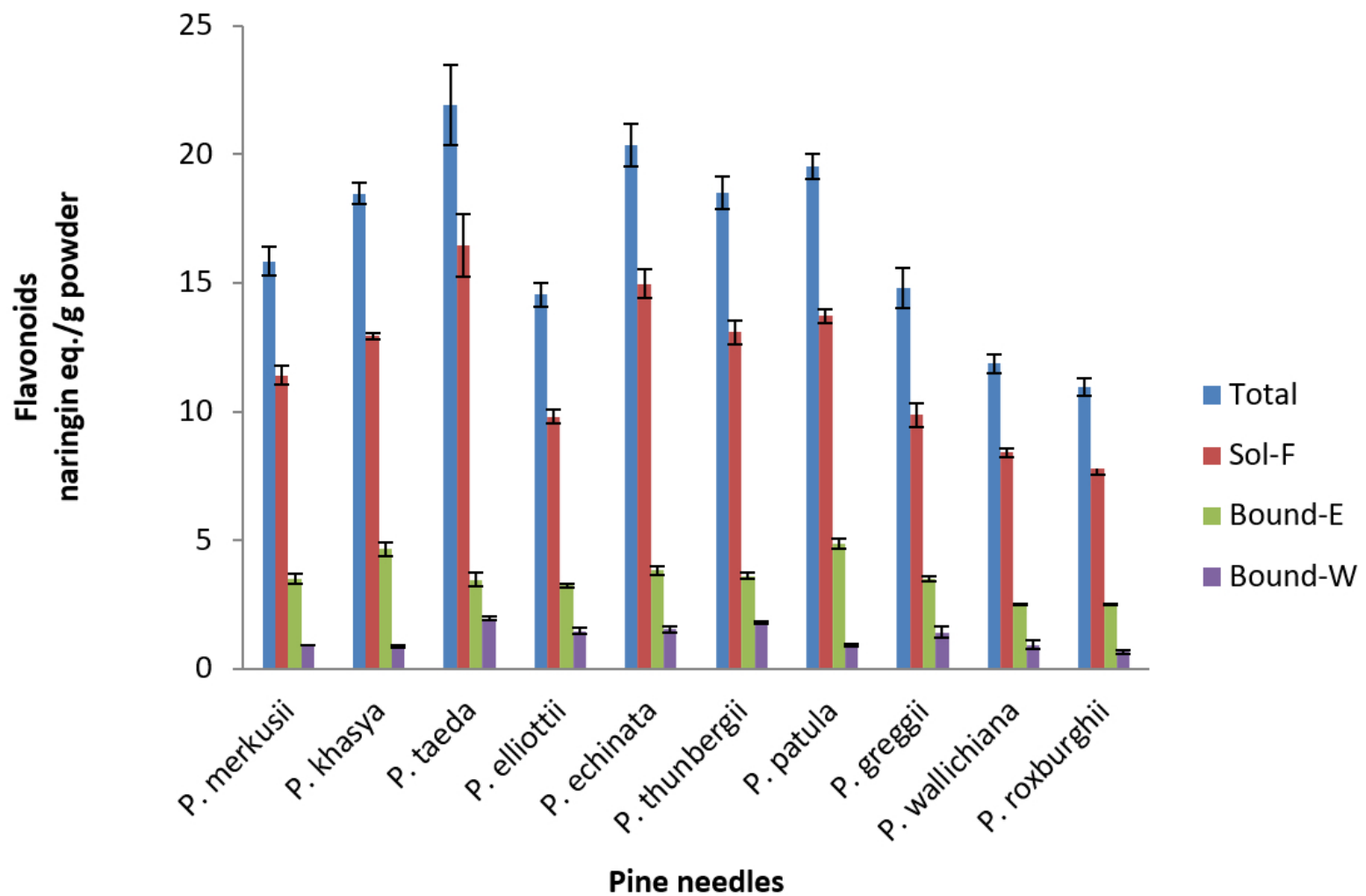

Figure 3. Total Flavonoids in soluble free (Soluble-F), bound ethyl acetate (Bound-E) and bound water (Bound-W) fractions from various pine needles. Values are mean \pm SD of triplicate measurements

$6.3 \mu$ mole Trolox/g) and $P$. thunbergii $(53.7 \pm 9.1 \mu$ mole Trolox $/ g)$. Pinus khasya had the highest Bound-W antioxidant activity (95.1 $\pm 8.5 \mu$ mole Trolox/g), followed by $P$. taeda $(90.1 \pm 6 \mu$ mole Trolox/g), P. patula (90.0 $\pm 7.9 \mu$ mole Trolox/g), P. wallichiana (66.2 $\pm 4.8 \mu$ mole Trolox/g), P. merkusii (56.9 $\pm 1.2 \mu$ mole Trolox/g), $P$. greggii $(49.4 \pm 4.9 \mu$ mole Trolox $/ g)$, P. roxburghii $(39.9 \pm 2.9 \mu$ mole Trolox/g), P. echinata $32.4 \pm 1.2 \mu$ mole Trolox/g), P. elliottii (26.2 \pm $3.2 \mu$ mole Trolox $/ g)$ and $P$. thunbergii $(24.4 \pm 2.1 \mu$ mole Trolox $/ g)$. The antioxidant capacities of the Soluble-F fractions of the ten pine needles were higher than those of Bound-E and Bound-W fractions of needles. $P$. taeda had the highest total antioxidant (Soluble-F+Bound-E+Bound-W) capacity (1308.6 $\pm 26.8 \mu$ mole Trolox/g), followed by P. patula (1162.0 $\pm 35.7 \mu$ mole Trolox/g), P. thunbergii (1114.7 $\pm 33.1 \mu$ mole Trolox/g), P. merkusii (1026.8 $\pm 35.1 \mu$ mole Trolox/g), P. khasya (898.8 $\pm 51.7 \mu$ mole Trolox/g), P. elliottii $(792.8 \pm 21.6 \mu$ mole Trolox/g), P. greggii $(670.3 \pm 30.2$ $\mu$ mole Trolox/g), P. roxburghii (576.7 $\pm 26.9 \mu$ mole Trolox/g) and $P$. echinata $553.5 \pm 20.9 \mu$ mole Trolox/g. The results show a direct correlation between phenolic concentration and antioxidant potential of species $\left(\mathrm{R}^{2}=0.847\right)$. This relationship has also been established in case of $P$. nigra needles using correlation analysis where a significant linear correlation between the antioxidant activity and total phenols, flavonoids and tannins contents was reported in the case of salazmani, pallasiana and nigra subspecies. However, no significant relationship between antioxidant activity and total phenol, flavonoids and tannins were recorded for laricio subspecies (Fkiri et al., 2018). Needles obtained from Pinus have been traditionally used to prepare drinks and as a medicine for several centuries in south-eastern Asian countries especially in China (Kim and Chung., 2000).
Further, Sharififar et al. (2007) noticed that free radical scavenging activity depends on the presence of bioactive compounds or synergistic effect of overall compounds present in the species. Hence, results related to antioxidant potential of these plants in this section indicated pines as a promising source of natural antioxidant foods and thus it can be used in the food industry to preserve or improve its quality.

\section{Antimicrobial activity}

The development of antibiotic resistance by microorganisms, specially bacteria, that threaten human health has become a major global clinical challenge. This has prompted the search for new antimicrobial substances from different sources, including plants (Ahmad and Beg, 2001; Bennett, 2008). In this context, the present study evaluated the antibacterial and antifungal potential of ten pine species. Antibacterial and antifungal activities of the different extracts obtained from ten species of Pinus were evaluated using the disk-diffusion method, and the results are presented in Table 3. Only Pseudomonas aeruginosa was resistant to each of three extracts of ten pine needles, while other gram negative bacteria showed greater degree of resistance in comparison to gram positive bacterial strains. This resistance can be attributed to the complexity of double layer cell membrane of gram negative bacteria in comparison to single membrane of gram positive bacteria (Hogg, 2005). For fungal strains, P. khasya, P. taeda and $P$. thunbergii showed growth inhibitory activity in each of three extracts against $C$. albicans, while $P$. merkusii, $P$. elliottii, Soluble-F and Soluble-E fraction of $P$. thunbergii showed growth inhibitory activity. 


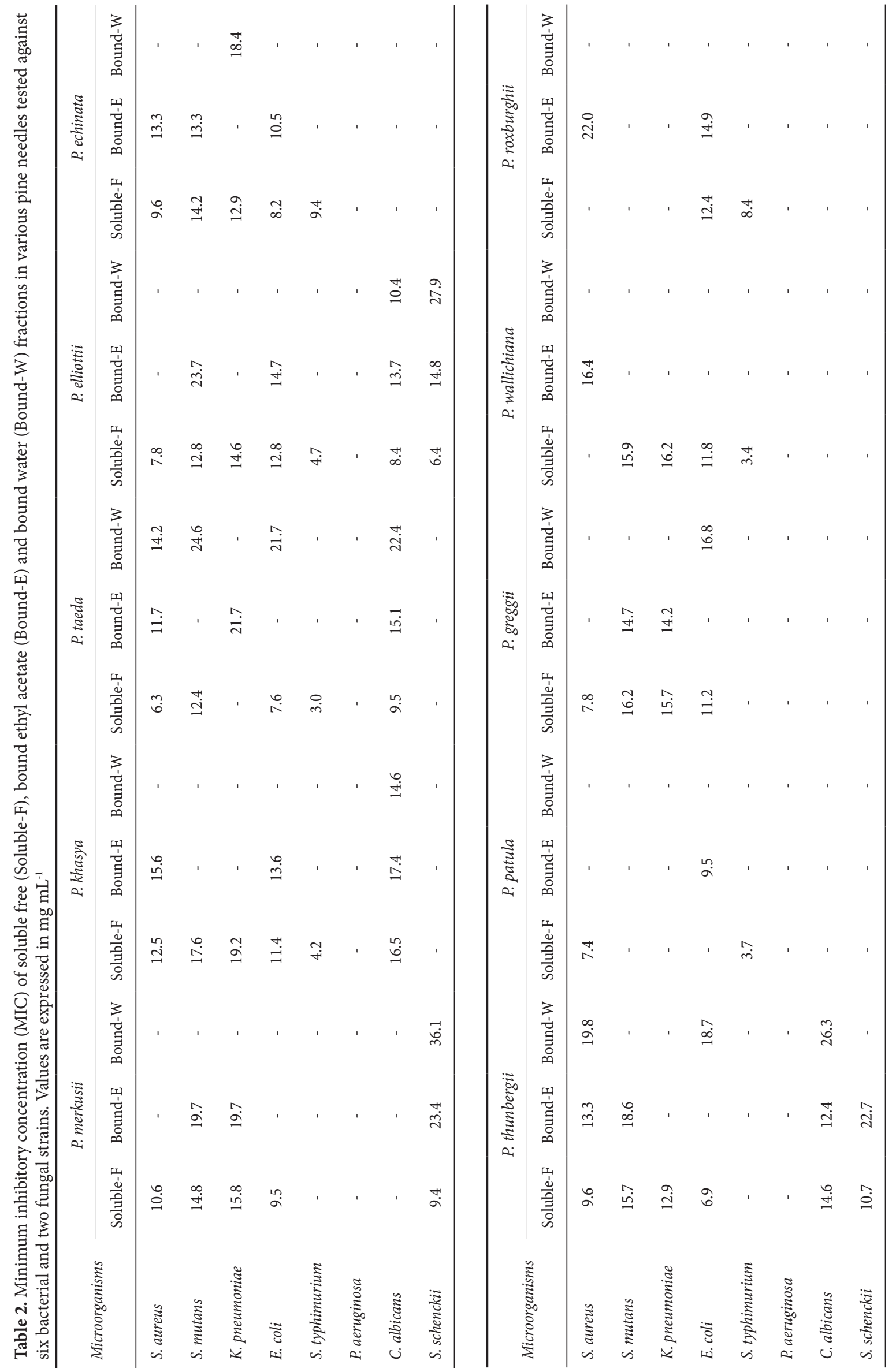




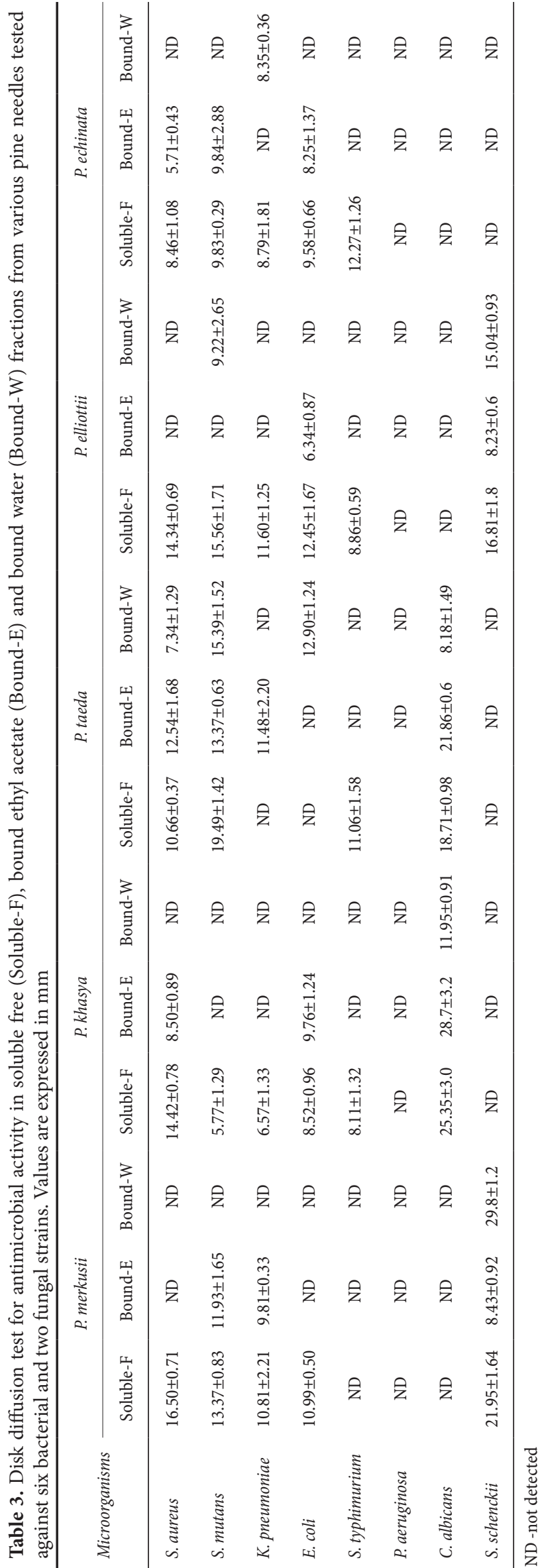

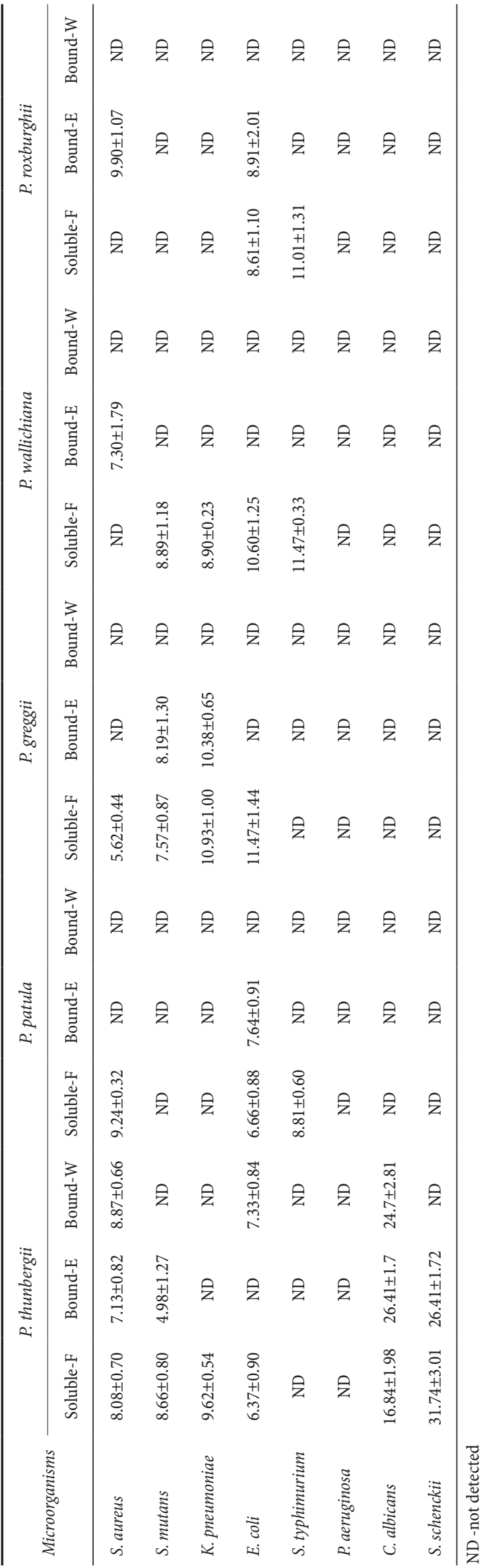




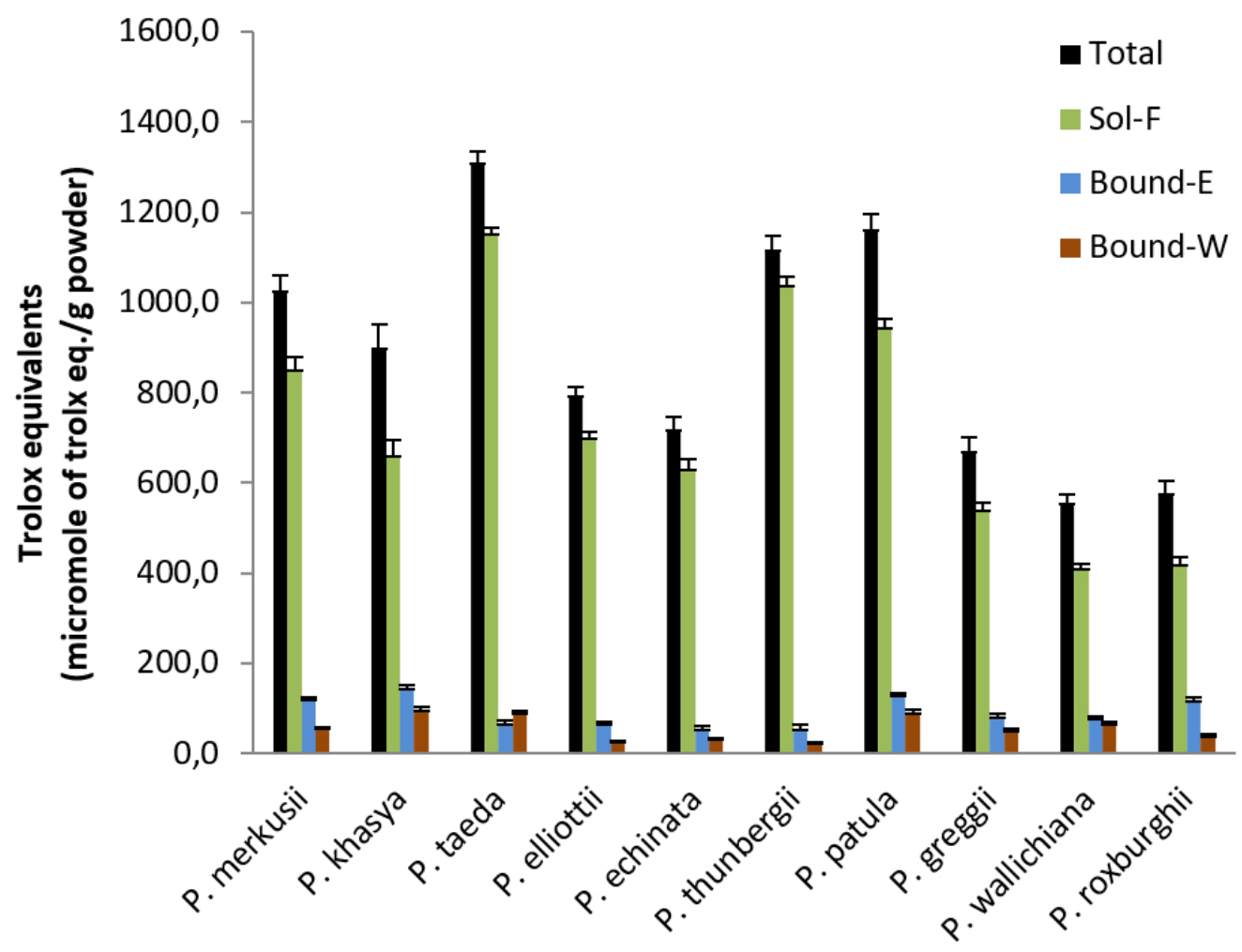

Pine needles

Figure 4. Antioxidant activity in soluble free (Soluble-F), bound ethyl acetate (Bound-E) and bound water (Bound-W) fractions from various pine needles. Values are mean $\pm \mathrm{SD}$ of triplicate measurements

Overall, lower MIC (Table 2) of extracts were needed to inhibit $S$. typhimurium $\left(<10.0 \mathrm{mg} \mathrm{mL}^{-1}\right)$. The highest MIC was obtained with the Bound-W extract of P. merkusii $\left(36.1 \mathrm{mg} \mathrm{mL}^{-1}\right)$ against $S$. schenckii. In contrast, lowest MIC was obtained with Soluble-F extract of $P$. taeda $\left(3.0 \mathrm{mg} \mathrm{mL}^{-1}\right)$. In this study, Soluble-F (soluble free) fraction revealed higher antibacterial activities in comparison to Bound-W and Bound-E indicating that most of the antibacterial constituents are extracted with soluble free fraction, while nearly every fraction in one species or another revealed growth inhibitory impact on selected fungal strains indicating presence of antifungal constituents in each fraction.

\section{Conclusion}

Our research furnishes the presence of several phenolic and flavonoid components and related antioxidant and antimicrobial properties in native and cultivated species of Pinus growing in Indian Himalayas. The antioxidant and antimicrobial activities reported in the current research confirm that the therapeutic value and biological efficacy of secondary metabolites in these species is very high and can lead to the development of novel, safe, and cost-effective drugs in future. However, need of hour is to conduct detailed and elaborative research on ethnobotanical and pharmacological investigations with simultaneous public awareness for the best utilization of medicinal and other beneficial properties of pines. Involvement of industrial entrepreneurs should also be promoted so that they can come forward with novel concepts and desired technologies and move towards sustainable use of pines. However, ecotoxicological implications must be imperative prior to marketization.

\section{Aknowledgement}

We are grateful to the University Grant Commission (UGC, India) for financial support provided by a grant to Lav Singh (Ref: 201314-NETJRF-10212-83). Author is also thankful to Head of the Department of Botany, Lucknow University for providing necessary research facilities.

\section{References}

Ahmad I., Beg A.Z. (2001). Antimicrobial and phytochemical studies on 45 Indian medicinal plants against multi-drug resistant human pathogens. J Ethnopharmacol 74, 113-123.

Alonso A.M., Guillen D.A., Barrosa C.G., Puertas B., Garcia A. (2002). Determination of antioxidant activity of wine by-products and its correlation with polyphenolic content. J. Agric Food Chem. 50(21):5832.5836.

Bennett P.M. (2008). Plasmid encoded antibiotic resistance: acquisition and transfer of antibiotic resistance genes in bacteria. Br J Pharmacol 153 (Suppl 1), S347-S357.

Brouillard R., Dangles O. (1993). Flavonoids and flower colour In: The flavonoids: Advances in Research since 1986 (Ed. By J. B. Harborne), London: Chapman and Hall. pp. 565-588.

Chang C., Yang M., Wen H., Chern J. (1996). Estimation of total flavonoid content in propolis by two complementary colorimetric methods. J. Food Drug Analysis 10,178-182.

Chung H.J., Hwang K.H., Yoo M.J., Rhee S. J. (1996). Chemical composition of pine sprouts and pine needles for the production of pine sprout tea. Korean J. Dietary Culture 11,274-276.

Ebrahimabadi A.H., Mazoochi A., Kashi F.J., Djafari Z., Batooli H. (2010). Essential oil composition and anti-oxidant and antimicrobial properties of the aerial parts of Salvia eremophila Boiss. from Iran. Food Chem Toxicol 48: 1371-76. 
Fkiri S., Mezni A., Ouarghi A., Ghazghazi H., Khouja L.M., Khaldi A., Nasr A. (2018). Variability of phenolic compounds and antioxidant efficacy in needles extracts of Pinus nigra Arn. Journal of New Sciences 3528-3525.

Hogg S. (2005). Essential Microbiology. John Wiley \& Sons, Ltd., Chichester, West Sussex, England.

Jeong J.B., Seo E.W., Jeong H.J. (2009). Effect of extracts from pine needle against oxidative DNA damage and apoptosis induced by hydroxyl radical via antioxidant activity. Food Chem Toxicol. 47, 2135-2141.

Kim N.Y., Jang M.K., Lee D.G., Yu K.H., Jang H., Kim M., Kim S.G., Yoo B.H., Lee S.H. (2010). Comparison of methods for proanthocyanidin extraction from pine (Pinus densiflora) needles and biological activities of the extracts. Nutr Res Pact 4, 16-22.

Kim K.Y., Chung H.J. (2000). Flavor compounds of pine sprout tea and pine needle tea. J. Agric. Food Chem. 48, 1269-1272.

Kwak C.S., Moon S.C., Lee M.S. (2006). Antioxidant, antimutagenic, and antitumor effects of pine needles (Pinus densiflora). Nutr Cancer. 56, $162-171$.

Maimoona A., Naeem I., Saddiqe Z., Jameel K. (2011). A review on biological, nutraceutical and clinical aspects of French maritime pine bark extract. J. Ethnopharmacol., 133: 261-277.

Mehra P.N. (1988). Indian Conifers, Gnetophytes Phylogeny of Gymnosperms. 121-143.

Negi S.P. (2009). Forest cover in Indian Himalayan states-An overview. Indian Journal of Forestry 32,1-5.

Reiger G., Muller M., Guttenberger H., Bucar F. (2008). Influence of altitudinal variation on the content of phenolic compounds in wild populations of Calluna vulgaris, Sambucus nigra, and Vaccinium myrtillus. J. Agric. Food Chem. 56, 9080-9086.
Sharififar F., Moshafi M.H., Mansouri S.H., Khodashenas M., Khoshnoodi M. (2007). In vitro evaluation of antibacterial and antioxidant activities of the essential oil and methanol extract of endemic Zataria multiflora Boiss. Food Control 18: 800-805. doi: 10.1016/j. foodcont.2006.04.002.

Singh D.K., Hajra P.K. (1996). Floristic diversity. In: Gujral GS, Sharma V, editors. Changing perspectives of biodiversity status in the Himalaya. New Delhi: British Council Division, British High Commission. 2338

Stafford H.A. (1988). Proanthocyanidins and the lignin connection. Phytochemistry 27, 1-6.

Sun J., Chu Y.F., Wu X., Liu R.H. (2002). Antioxidant and antiproliferative activities of common fruits. J Agric Food Chem. 50, 7449-7454.

Tegelberg R., Julkunen T.R., Aphalo P.J. (2004). Red: Far red light ratio and UV-B radiation: their effects on leaf phenolics and growth of silver birch seedling. Plant Cell Environ. 27(8), 1005-1013.

Velioglu Y.S., Mazza G., Gao L., Oomah B.D. (1998). Antioxidant activity and total phenolics in selected fruits, vegetables, and grain products. J. Agric. Food Chem. 46, 4113-4117.

Wildi B., Lutz C. (1996). Antioxidant composition of selected high alpine plant species from different altitudes. Plant Cell Environ. 19, 138-146.

Yoon H.K., Luke R. (2010). Howard. Phenolic Composition and Antioxidant Activities of Different Solvent Extracts from Pine Needles in Pinus Species. J Food Science and Nutrition 15, 36-43.

Zhang M., Guo B., Zhang R., Chi J., We Z., Xu Z., Zhang Y.,Tang X. (2006).Separation, purification and identification of antioxidant compositions in black rice.AgricSci China5,431-440. 